
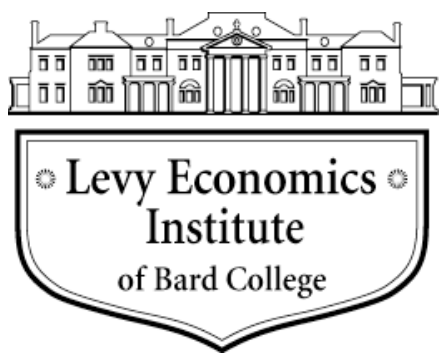

Working Paper No. 739

\title{
On the "Utilization Controversy": A Theoretical and Empirical Discussion of the Kaleckian Model of Growth and Distribution
}

by

\author{
Michalis Nikiforos \\ Levy Economics Institute of Bard College
}

November 2012

\begin{abstract}
*This paper is part of my recently completed Ph.D. dissertation at the New School for Social Research (NSSR). An earlier version of it has appeared in the working paper series of the economics department of the NSSR (16/2011). I would like to thank Duncan Foley, Peter Skott, Lance Taylor, Luca Zamparelli, Laura Barbosa de Carvalho, Christian Schoder, Jonathan Cogliano, and Jeanne Shu as well as the participants in the 38th Annual Conference of the Eastern Economic Association in New York and the 15th Conference of the Research

Network Macroeconomics and Macroeconomic Policies (FMM) in Berlin for useful comments and suggestions. The usual disclaimer applies. Financial support from the Greek State Scholarships Foundation is gratefully acknowledged.
\end{abstract}

The Levy Economics Institute Working Paper Collection presents research in progress by Levy Institute scholars and conference participants. The purpose of the series is to disseminate ideas to and elicit comments from academics and professionals.

Levy Economics Institute of Bard College, founded in 1986, is a nonprofit, nonpartisan, independently funded research organization devoted to public service. Through scholarship and economic research it generates viable, effective public policy responses to important economic problems that profoundly affect the quality of life in the United States and abroad.

Levy Economics Institute

P.O. Box 5000

Annandale-on-Hudson, NY 12504-5000

http://www.levyinstitute.org

Copyright (C) Levy Economics Institute 2012 All rights reserved 


\begin{abstract}
This paper examines the "utilization controversy" around the Kaleckian model of growth and distribution. We show that the Federal Reserve data on capacity utilization, which have been used by both sides of this debate, are the wrong kind of data for the issue under examination. Instead, a more appropriate measurement can be derived from the data on the Average Workweek of Capital. We argue that the long-run dynamic adjustment proposed by Kaleckian scholars lacks a coherent economic rationale, and provide an alternative path toward the endogeneity of the desired utilization at the micro and macro levels. Finally, we examine the proposed adjustment mechanism econometrically. Our results verify the endogeneity of the normal utilization rate.
\end{abstract}

Keywords: Kaleckian; Long Run; Economies of Scale; Utilization

JEL Classifications: B50, E12, E22 


\section{Introduction}

The Kaleckian model of growth and distribution is a standard analytical tool of modern nonmainstream macroeconomics. The attractiveness of its theoretical framework lies in the combination of the distribution of income and the existence of classes with the principle of effective demand. In that sense, it is able to combine the Keynesian emphasis on demand with classical ideas of political economy. Finally, it has the flexibility to accommodate different views and approaches and it is no accident that it has been the field for many recent debates among different economic traditions.

At the same time, the analytical framework of the model has been been subjected to severe critique. The most fundamental argument of this critique is that in the long run the rate of capacity utilization has to return to its normal, desired or target rate. Since - the critique goes - firms determine their desired rate of utilization under the cost minimizing principle, there is no reason to change this desired rate, unless the underlying reasons associated with the cost minimization problem change. The deviation of the actual rate from the desired rate is not one of these reasons. Therefore, the results of the Kaleckian model apply only in the short run. In the long run we either have to find a way for the actual level of utilization to adjust to the exogenous desired level (within the model's framework), or abandon the model in favor of other formulations where the actual level of utilization is equal to its exogenous desired level in the long run. Consequently, in the long run the Keynesian characteristics of the model cease to exist, there is no space for the paradox of cost or the paradox of thrift.

This critique is reinforced by the Federal Reserve data. For the last six decades, the period these data are available for, utilization of capacity gravitates around a desired rate of approximately 80 percent.

The "Kaleckian side" has conceded that in the long run the two rates must equalize. However, they argue that it is the desired rate of utilization which adjusts to the actual rate and not the other way around. Although this argument is formally correct it lacks a coherent economic rationale.

In the present paper, we explain why the Federal Reserve data on capacity utilization - which have been used by both sides in this debate - are not appropriate for answering whether or not the desired of utilization is endogenous in the long run. We argue that these data are stationary by construction and they represent how much capacity is utilized compared to the desired rate of utilization. Therefore we need to rely on other data in order to examine if the utilization rate is stationary or not in the long run. A solution to this problem is to examine the behavior of the average workweek of capital, where the full capacity is defined as $24 * 7=168$ hours per week. We present several efforts to estimate the average workweek of capital, which show that there has been an increase of the workweek of capital, and therefore of utilization. From this point of 
view the utilization of capital is far from stationary.

A recent paper (Nikiforos, 2012) shows that at the firm level, the desired utilization rate can become endogenous if we take into account the behavior of the returns to scale; the firm will tend to utilize its capital more as the output grows, if there are increasing returns to scale and the rate of the returns to scale decreases. In the present paper we show how this micro behavior can be compatible with an endogenous desired utilization rate at the macro level.

Finally, we examine the proposed adjustment mechanism using a simple Auto-RegressiveDistributive-Lag (ARDL) model. We derive the desired rate of utilization by de-trending the series on the Average Workweek of Capital and we regress it against the Federal Reserve data on utilization. Our results provide evidence that the desired rate of utilization is indeed endogenous in the long run.

Before proceeding to the analysis of the thesis of this paper it would be useful to briefly discuss the concept of capacity utilization and its relation with capital utilization. The two concepts are often used within the aforementioned debate, but it is not always clear if people refer to one or the other.

The difficulty with the concept of capacity utilization arises because of the ambiguous meaning of capacity. How does one define capacity? Different answers have been given to this question. The most straightforward definition of capacity is the engineer capacity: the maximum level of output obtained if we use the quasi-fixed factors of production 24 hours per day and 7 days per week at the maximum possible speed of operation. The full capacity of a firm whose only quasi-fixed production factor is a factory is the output that would be produced if this factory was working 168 hours per week at full speed. We can also define a statistical concept of capacity. This is usually done by deriving a peak-to-peak trend of output or applying a filter (e.g. Hodrick and Prescott, 1997) to the time series of output.

Besides these two concepts, we can define capacity as an economic (as opposed to an engineer or statistical) concept. Two alternative definitions have been employed. Preferred capacity is usually defined as the level of capacity specified with the cost-minimization principle. On the other hand practical capacity (or full production) is defined as the level of production where the variable (non-quasi-fixed) inputs are used at their maximum level. These definitions are not identical but are close, both from a theoretical and an empirical point of view. In section 4.1 we show that the change in the questionnaires of the Census from the one definition to the other led to a small discrete change in the reported utilization (around four percentage points) ${ }^{1}$. These definitions are close to what we have called desired or normal utilization.

Within the context of these definitions the importance of the distinction between capacity and

\footnotetext{
${ }^{1}$ A detailed discussion of the different definitions is provided among others by Klein (1960), Berndt and Morrison (1981), Morrison (1985), Bresnahan and Ramey (1994), Mattey and Strongin (1997) and Corrado and Mattey (1997).
} 
capital utilization becomes more clear. More frequently than not the two terms are used interchangeably with or without always realizing it. However, we should note that there are important differences between them. The utilization of capital expresses how much of the capital stock, as a distinct input of production, is utilized, while capacity utilization measures how much output is produced vis-à-vis how much output could be produced. Capital and capacity utilization would be the same only if capital is the only quasi-fixed factor of production.

In this paper we will not make a distinction between the two concepts. In other words we will assume that capital is the only quasi-fixed input in production. With a Leontief-type production function and with the assumption of elastic supply of labor, an assumption almost universal in the related literature, the ratio of potential output to capital in place is equal to the ratio of capital services (or utilized capital) to actual output. As a result $\bar{Y} / K^{i p}=Y / K^{s}$, so the two definitions of utilization coincide ( $K^{S}$ stands for the capital services). Therefore in the series of articles and books which discuss the issue of the long run rate of actual and desired utilization, explicitly or implicitly, the two definitions are used interchangeably. We will follow the same path but we should keep in mind the difference between the two and the prerequisites for their coincidence.

\section{The Basic Setup of the Model}

The Kaleckian model of growth and distribution is built on the ideas of the classical political economists, John Maynard Keynes and Michal Kalecki (e.g.1971). In its contemporary form it has been developed by Steindl (1952), Rowthorn (1981), Taylor (1983, 1990, 2004), Dutt (1984, 1990), Amadeo (1986), Kurz (1990) and Marglin and Bhaduri (1990). It is worth noting that the model under examination and its broader analytical framework has been baptized with various names. Two of the most common names within the literature are "Structuralist" and "PostKeynesian".

The analysis evolves around the concepts of demand and distribution. In its basic setup, demand is determined by the saving behavior of workers and capitalists and the investment behavior of the firms. The total income of the economy is distributed between wages and profits.

Investment (normalized for capital stock) can be defined as $g^{i}=I(\pi, u)$, where $\pi$ is the profit share, $Y$ and $\bar{Y}$ is output and potential output respectively and finally $u=Y / \bar{Y}$ is capacity utilization with $I_{\pi}>0$ and $I_{u}>0$ (the subscript stands for the partial derivative for this variable). On the other hand, total saving (normalized for the capital stock) is $g^{s}=S(\pi, u) . S_{u}$ and $S_{\pi}$ are positive $^{2}$.

For the purposes of the present paper we will assume the following functional form for the investment function

\footnotetext{
${ }^{2}$ It beyond the scope of this paper to go into the details of the Kaleckian model, which are widely known. A recent summary is provided among others by Nikiforos and Foley (2012).
} 


$$
g^{i}=\gamma+\alpha\left(u-u_{d}\right)+\beta \pi
$$

where $u_{d}$ is the desired rate of utilization and $\alpha, \beta>0$. The only difference in this formulation with the generic one above is that investment does not react to the level of utilization per se but to the deviation of the level of utilization from its desired rate. This kind of investment function has been proposed by Steindl (1952) and Amadeo (1986) and more recently it has been used by Lavoie $(1995,1996)$ and Dutt (1997).

Moreover, for reasons of convenience, we will assume that the workers do not save, and the saving behavior of the economy boils down to the familiar Cambridge equation

$$
g^{s}=s r=s \pi \rho u
$$

where $s$ is the saving rate of the capitalists, $r$ is the profit rate and $\rho=\bar{Y} / K^{i p}$ is the ratio of the potential output to the capital stock in place.

The equilibrium level of utilization $\left(u^{*}\right)$ will be such as to equate the total saving and total investment $g^{i}=g^{s}$ for the exogenously given distribution. From equation (1) and (2) it is easy to see that

$$
u^{*}=\frac{\gamma-\alpha u_{d}+\beta \pi}{s \pi \rho-\alpha}
$$

The equilibrium is stable if $s \pi \rho>\alpha$, that is if savings react more than investment to changes of utilization; what is usually called Keynesian stability condition ${ }^{3}$.

From equation (3) we can see that the paradox of thrift holds, since $\partial u^{*} / \partial s$ are both negative. Moreover, if a redistribution of income against capitalists will tend to increase utilization and the growth rate $\left(\partial u^{*} / \partial \pi<0\right)$ we are under a stagnationist, wage-led, or under-consumptionist regime, while if $\partial u^{*} / \partial \pi>0$ are under an exhilarationist, profit-led regime where the redistribution in favor of the capitalists leads to higher output $-\partial u^{*} / \partial \pi$ and $\partial g^{*} / \partial \pi$ are positive.

Aside from the demand schedule, where the distribution of income is the exogenous variable, we can define the distributive schedule where the causality runs in the other direction. The distributive schedule expresses how output is distributed among wage and profit earners, and how distribution reacts to changes in utilization. For our purposes we will assume that the distribution of income is exogenously determined, hence

$$
\pi=\bar{\pi}=1-\bar{\psi}
$$

\footnotetext{
${ }^{3}$ For the equilibrium to make sense it must also be true that $\gamma-\alpha u_{d}+\beta \pi>0$.
} 
Foley and Michl (1999) refer to this assumption as the classical conventional wage share, due to the view held by the classical economists that the distribution of income-at least in the long run - is exogenously determined at the subsistence level of the workers (which in turn is conventional). As a result of the exogenous distribution assumption, the impact of a change in distribution on utilization can be inferred by equation (3).

\section{The utilization controversy}

\subsection{The Critique}

The Kaleckian model has been criticized on many levels. For example Skott $(2010,2012)$ questions the assumption that saving reacts more than investment to changes of income, what we called Keynesian stability condition, and Steedman (1992, p.125) poses some "questions concerning the Kaleckian theory of pricing and the closely related theory of distribution".

However, the most persistent critique is related to the inability of the Kaleckian model to equate the actual rate of capacity utilization $\left(u^{*}\right)$ with the exogenously given desired - or normal or planned-rate $\left(u^{d}\right)$. Committeri (1986, p.170), referring to the contributions of Rowthorn (1981) and Amadeo (1986), writes that "there is the possibility of utilization being different from its normal degree, even in states of equilibrium (and indeed, actual and normal utilization would coincide only by a mere fluke)." Auerbach and Skott (1988, p. 52) claim that a steady growth path with $u^{*} \neq u^{d}$ is ruled out, i.e. $u^{*}=u^{d}$ along the steady growth path ${ }^{4}$ " and they add on the next page that "it is inconceivable that utilization rates should remain significantly below the desired level for any long period."

The failure of the Kaleckian model to equate the actual to the desired rate of capacity utilization has led many to consider it as relevant only in the short run. The title of the paper by Dumenil and Levy (1993) is telling: "Being Keynesian in the Short Term and Classical in the Long Term". They provide a mechanism for the convergence of the economy from the short term Keynesian/Kaleckian equilibrium "with any capacity utilization rate" to the long run classical equilibrium "with a normal capacity utilization rate".

Heinz Kurz (1986) argues that the normal or desired level of utilization of a firm is based on a cost-minimizing decision process ${ }^{5}$, analogous to the process for choosing the technique of production. He shows that the normal rate of utilization for such a firm is exogenous and structurally given and will not respond to changes in demand. Desired utilization will only change in response to technological changes or changes in the norms that determine the relative cost of

\footnotetext{
${ }^{4}$ Auerbach and Skott (1988) use $u$ and $u^{*}$ to symbolize the actual and the desired rate of utilization respectively. The change has been made for reasons of consistency.

${ }^{5}$ Quoting Sraffa (1960) Kurz writes that the normal rate of utilization "will be exclusively grounded on cheapness"
} 
labor between the two shifts. Kurz uses the classical parable of the center of gravitation. He explains that the actual rate of utilization can gravitate for an extended period of time around its normal rate due to changes in demand, but the gravitation does not affect its center i.e., the normal rate itself.

Along the same lines, Shaikh (2009) defines the normal utilization rate as the "rate at which the operation of a given plant is most profitable in the long run" (p.459). With the help of a hypothetical firm similar to that of Kurz (1986) he argues that changes in the actual utilization rate have "no effect whatsoever on the normal rate of capacity utilization" (p. 461, emphasis in the original).

In conclusion, the critique can be summarized in the following arguments:

1. In the long run, utilization cannot be different from its desired rate. This is an intuitive argument. It does not make sense that the firm would choose to underutilize or over-utilize its capital ad infinitum if there is another level of utilization which is more profitable.

2. The desired rate is determined on the basis of the cost-minimizing principle.

3. The desired rate for a firm that minimizes its cost is exogenously determined.

4. Thus, in the long run, the rate of utilization gravitates around a structurally given and exogenous desired rate of utilization.

The critique is serious. If it is correct, the conclusions of the model apply only in the short-run. In the long run, we either have to turn back to the classical results, where there is no room for the paradox of thrift and the paradox of cost - a higher saving rate leads to higher growth and a lower real wage and wage share is always related to lower profit rate and growth - or we have to seek other formulations which can potentially establish Keynesian results. Committeri (1986), Dumenil and Levy (1993) and Shaikh (2009) are in favor of the first approach while Skott (2010, 2012) supports the latter.

\subsection{The Kaleckian Response}

In response to this critique, the proponents of the Kaleckian model have argued that in the long run it is the desired rate of utilization that converges towards the actual rate and not the other way around. Amadeo (1986, p.148) says "we should be prepared to examine the possibility of utilization being an endogenous variable even in the long period". A few pages later (p. 155) he adds: "Indeed one may argue that if the equilibrium degree is systematically different from the planned degree of utilization, entrepreneurs will eventually revise their plans, thus altering the 
planned degree. If, for instance, the equilibrium degree of utilization is smaller than the planned degree $\left(u^{*}<u_{d}\right)$, it is possible that entrepreneurs will reduce $u_{d}$."6

Formally, what he proposes is an adjustment process described by the following dynamic equation

$$
u_{d}=\mu\left(u^{*}-u_{d}\right)
$$

where $\mu>0$ and $i_{d}$ is the derivative of $u_{d}$ with respect to time.

In a series of articles, Lavoie (1995, 1996), Lavoie et al. (2004) and more recently Hein et al. (2012) are more explicit. They argue that the firms apart from the capital/capacity they own and they operate according to the principle of cost minimization - as described by Kurz (1986) have "some plants or segments of plant [that] remain idle in normal positions"(Lavoie et al., 2004, p.133). This kind of complete idleness of a part of capital is maintained by firms in order to face the uncertainty of future demand. They conclude (on the same page) that "the normal rate of capacity utilization, in that context, is thus a convention [emphasis added], which may be influenced by historical experience or strategic considerations related to entry deterrence. Although firms may consider the normal rate of capacity utilization as a target, macroeconomic effective demand effects might hinder firms from achieving this target, unless the normal rate is itself a moving target influenced by its past values"(Lavoie et al., 2004).

Finally, Amitava Dutt (1997, p.247) explains the endogeneity of the desired rate of utilization in terms of "strategic considerations of the firms". The firms will reduce their desired utilization rate if they "expect a higher rate of entry than at present" and they consider the entry threat to be "proportional to the investment rate", thus $i_{d}=\mu^{\prime}\left(g_{0}-g^{*}\right)$, which with the help of equations (1) and(3) can be transformed into equation $(5)^{7}$.

Equation (5) is usually coupled with a dynamic equation with Harrodian characteristics for the expected growth rate, $\gamma$. These two dynamic equations describe the trajectory of the economy in the long run. A brief analysis of this dynamic system can be found in the Appendix.

The important feature of this formulation is that the economy remains demand driven in the long run: the paradox of thrift and the paradox of cost continue to hold. A higher saving rate will lead the economy to a steady state with a higher level of utilization and growth rate. Interestingly, in the long run the economy cannot be profit-led. A higher profit share decreases the steady state level of utilization and growth.

\footnotetext{
${ }^{6}$ Amadeo (1986) uses $u_{n}$ for the planned degree of utilization.

${ }^{7}$ Implicitly it is assumed that $g_{0}=\gamma+\beta \pi$.
} 


\subsection{Why The Response Is Unconvincing}

From a formal point of view, the arguments of the preceding section answer the critique regarding the impossibility of a long run deviation of the actual rate of utilization from the desired one; the actual and the desired rate are equal in the long run. However, they fall short in explaining why the desired rate of utilization behaves in the way it is described in equation (5). Stated differently, why would a deviation of the actual utilization from the desired rate induce the entrepreneurs to revise their desired rate?

The argument of the conventional desired rate of utilization is not convincing for two reasons. First, there is no particular rationale behind distinguishing excess capacity in the form of lower than full speed of operation, or lower than full time of operation (one shift instead of two or three shifts), or in the form of totally idle capacity, of "some plants or segments of plant remain[ing] idle". If a firm operates at $80 \%$ capacity in order to be able to respond to an unexpected increase in demand or to deter the entry to possible competitors ${ }^{8}$ it can do it either by lowering the speed of its operation to $80 \%$, or by operating its plants $80 \%$ of the time it would otherwise operate them, or by keeping a $20 \%$ of its productive capacity idle, or by a combination of all three. There is no general a priori reason - theoretical or based on the actual experiencethat makes the last method superior to the two first. Under certain technologies it would probably be more profitable for the firm to choose the idleness method, but this would depend on certain characteristics of an industry and it is not a general rule. On the contrary we could think of reasons why the firm would favor the first two methods compared to the third one (e.g. adjustment costs for hiring labor).

Moreover, even if this claim were true, the utilization rate does not become a convention. The need of the firm to face unexpected increases in demand is an objective and non-conventional reason for keeping a part of its capacity idle. A behavior of the desired utilization rate as described in equation (5) based on the need of the firm to face unexpected demand, would mean that when the actual rate of utilization is lower than the desired rate, the firm expects more volatile demand and thus decreases its desired rate of utilization, but it is hard to see why this would happen.

In general, as it becomes clear in the theory of utilization-among othersMarris (1964), Winston (1974), Betancourt and Clague (1981), Kurz (1986), Nikiforos (2012) - the level of the utilization of its capacity is one of the most important decisions for a firm, analogous to the choice of technique. It is hard to see why an entrepreneur will treat a decision of such importance for the profitability and the survival of its firm, merely as a convention.

\footnotetext{
${ }^{8}$ The argument of low utilization as an entry deterrence mechanism is made by Spence (1977).
} 


\section{Data on Utilization}

\subsection{The Federal Reserve Data On Utilization}

The Federal Reserve Board (FRB) data on capacity utilization have been used by both sides in the debate ${ }^{9}$. Lavoie et al. (2004) filter the data with the Hodrick-Prescott (HP) filter and they argue that the fluctuations of the HP-filtered series prove that the desired rate adjusts as described in equation (5). They also provide an econometric justification for their claim using these data ${ }^{10}$.

In figure 1 we present the FRB capacity utilization series for the US economy for the period 1948 to 2007. It is hard to see how these data support the claim of an endogenous utilization rate. From the fitted lines it becomes obvious that the rate of capacity utilization tends to gravitate around a constant rate over a prolonged period of time, approximately $83 \%$ in the period 1948 to 1980 and approximately $79 \%$ in the period 1980 to 2007 . This change can be attributed to a change of the structural characteristics behind the desired rate of utilization. For example, Spence (1977) would argue that this shift is the result of an increase in the concentration in the market and as a result the firms need to lower their utilization rate to deter the entry of the competitors. However, we do not have to go that far. Morin and Stevens (2004, p.9), in a paper describing the construction of the FRB capacity utilization index ${ }^{11}$, argue that a big part-if not the whole- of this decrease is due to changes in the definition of capacity in the questionnaires of the surveys which are used to construct the index. These changes led to a "discrete shift" of the index around " 4 percentage points". It is probably no coincidence that this is the difference between the two horizontal fitted lines.

Similarly, in the case of the HP filtered series of utilization, we observe a remarkably stable desired rate of utilization - if we interpret the HP-series as representing the desired rate. Over the whole period there are some minor fluctuations, but they are not enough to support the hypothesis of an endogenous rate of utilization. If the series is HP-filtered for the period before and after 1980 we will end up with almost horizontal lines, as in the case of the linear fits, which, taken together with the change of the estimated utilization rates because of the changes in the questionnaire, leads to the conclusion that the desired rate of utilization is constant.

The FRB utilization behaves exactly in the way described by Kurz (1986): demand causes gravitation around the normal rate and in fact "it cannot be procluded that deviations of the actual situation from the "normal" one, may become large, and remain so for a long period of time" (p. 40), but the normal rate itself is not affected by these deviations.

Therefore, if one relies on the capacity utilization index of the Federal Reserve, the argument

\footnotetext{
${ }^{9}$ The data can be found at http://www.federalreserve.gov/releases/g17/caputl.htm

${ }^{10}$ They use data on capacity utilization from Statistics Canada, which are practically the same with those of the FRB

${ }^{11}$ The online documentation of the Industrial Production and Capacity Utilization in the website of the Federal Reserve (2009) is a short version of this paper.
} 


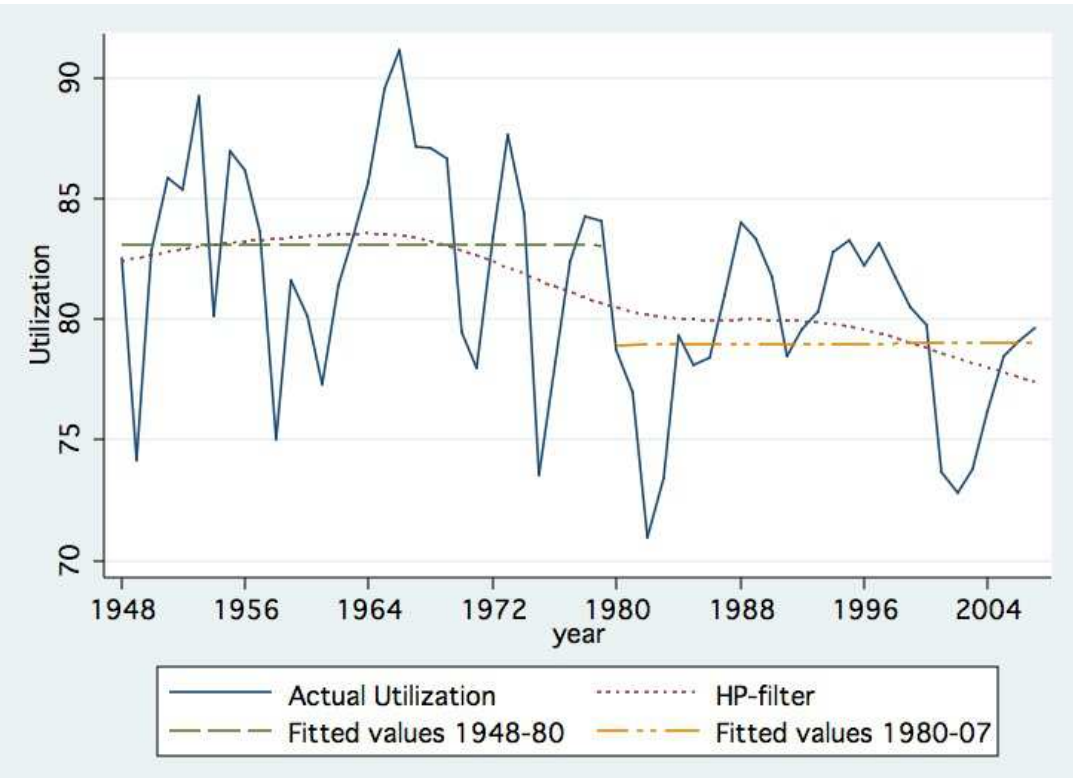

Figure 1: Capacity Utilization from the FED dataset. Annual data, for the period 1948-2007.

of an endogenous rate of capacity utilization seems unwarranted. Instead, there seems to exist an exogenous desired rate of about $80 \%$, around which the actual rate gravitates.

\subsection{Why The FRB Data Are Inappropriate}

However, if we pay a little closer attention to the way these data are constructed, it becomes clear that they are inappropriate to judge whether the desired rate of utilization is (or is not) endogenous in the long run. For that purpose the paper by Morin and Stevens (2004) is very useful. The index is based on the Survey of Plant Capacity (SPC) which is conducted by the United States Census Bureau ${ }^{12}$. In the questionnaires of the SPC the plant managers are asked to specify the "full production capability of their plant - the maximum level of production that this establishment could reasonably expect to attain under normal and realistic operating conditions fully utilizing the machinery and equipment in place". Among the instructions they are given is to "assume number of shifts, hours of plant operations, and overtime pay that can be sustained under normal conditions and a realistic work schedule [emphasis in the original]." The results of this questionnaire are then processed and aggregated in order to produce the series we presented in figure 1 .

Let us now put ourselves in the shoes of a plant manager who answers the questionnaire. Assume that over a period of years our plant works 5 days per week, 8 hours per day. Under these normal and realistic conditions the number of shifts is one and the hours of plant operations per week are forty. We can also assume that the full production capacity of the plant under these

\footnotetext{
${ }^{12} \mathrm{~A}$ copy of the questionnaire can be found online at http://bhs . econ. census .gov/bhs/pcu/pdf/10_mqc2.pdf
} 
normal conditions is 100 units. The plant manager wants to be able to face unexpected demand increases (or to deter the entry of the competitors in the market), so the plant is working on average at the $80 \%$ of its full capacity ${ }^{13}$. Therefore, on average the production of the plant will be 80 units vis-à-vis a full production capability of 100 units, that is utilization of capacity around $80 \%$. Of course when the economy is doing well and the demand is high the plant manager will increase the speed of production, or will not let the workers leave earlier - they might even work overtime - or she will utilize the idle part of the plant. In these "fat cow" years, when she fills the SPC questionnaire the production will be higher than 80 units and therefore the utilization will be higher than $80 \%$. In years of economic downturn for the same reasons the utilization will be lower than $80 \%$.

Next, imagine that our firm is doing well and after an extended period of high demand the plant manager decides to add a second shift. Over a period of years the plant works 5 days per week, 16 hours per day. Under these new normal and realistic conditions the number of shifts is two and the hours of plant operations per week is eighty. The full production capability of this plant under the new normal conditions is 200 units (we abstract from any kind of economies of scale or other reasons that would make this product to be different than 200). The plant manager still worries about competition and being able to face unexpected demand. That is why she "runs" her plant on average at the $80 \%$ of its full capability. Therefore, on average the production of the plant will be 160 units vis-à-vis a full production capability of 200 units, that is utilization of capacity around $80 \%$. The cyclical fluctuations effects still apply.

If after a few years the demand for the products of the firm permanently decreases and the manager decides to drop the second shift, we will be back to the original situation.

The conclusion of this simple example is that the FRB index of capacity utilization by construction gravitates around a structural exogenous level of utilization and by construction is stationary. In the online documentation of the Federal Reserve (2009) it is made explicit that "a major aim is that the Federal Reserve utilization rates be consistent over time so that, for example, a rate of 85 percent means about the same degree of tightness that it meant in the past." In that sense the FRB utilization index is a proxy for the deviation of $u^{*}$ from $u_{d}$ and gives us no information about the $u_{d}$ itself.

Therefore, in order to examine the behavior of the utilization over the long run, we have to go one step ahead and look for other measures, which can capture if the plant "runs" for one or two (or three) shifts, if it runs during the weekends and other possibilities. The obvious method to do that is to compare the number of hours the plant works with the maximum hours it can work. The maximum hours the plant can work within one week period is $24 \times 7=168$ hours. Thus, a more appropriate measure of utilization for our purpose is the ratio of hours worked by

\footnotetext{
${ }^{13}$ Note that there is no general reason why the manager either does not "run" the plant at its full speed, or lets the workers go home earlier, or keeps a part of the plant idle.
} 
the plant per week over 168. This measure is not without problems but it is more appropriate for our discussion. In the next section we present various attempts to measure utilization, which capture the amount of time the capacity is utilized.

\subsection{Other Measures Of Utilization}

A first attempt of measuring capital utilization as the ratio of the time the plant worked over an absolute amount of time (number of hours per week or year) was made by Foss (1963). He used data on power equipment from the Census of Manufactures and estimated the theoretical maximum of electrical consumption of the machinery-in-place for a one-year period. He then estimated the utilization rate of the machinery by comparing this theoretical maximum to the actual consumption of electricity (available from the Census of Mineral Industries). Foss finds that the "equipment utilization ratio from 1929 to an approximately comparable high employment year in the 1950's [1955] shows an increase of almost 45\%". Foss's methodology has several drawbacks related with the assumptions he made to estimate his theoretical maximum. However two main conclusions, which would be confirmed by later studies, came out: i) the capital equipment lies idle most of the time and ii) there is a clear upwards trend in the utilization of capital equipment.

Foss (1981a,b) uses a more direct method. He utilizes data from the 1929 Census of Manufactures and the 1976 Survey of Plant Capacity undertaken by the Census Bureau on weekly plant hours worked by manufacturing plants, which he then aggregates. The results are summarized in table 1 . We can see that over the period 1929 to 1976 the average workweek of capital increased around 25\%. If we take into account that 1929 was a year at the peak of the economic cycle while 1976 was close to the bottom, the increase is higher. This increase occurred in the face of a decline in the average workweek of labor "from a customary 50 hours per week in 1929 to a 40-hour standard in 1976."

In a later study Foss (1984) makes use of the Area Wage Surveys of BLS, covering metropolitan areas for high employment periods, 1959-60, 1969 and 1978-79. The percentage of workers employed on second and third shifts for all manufacturing industries combined is used to interpolate the average weekly plant hours (of table 1). The estimates between "pairs of endpoints" is derived by straight line interpolation. Thus the annual estimates between 1929 and 1976 constitute a "high employment trend-line". The results are presented on the left hand side of the dashed line in figure 2.

Certain industries, because of some particular characteristics of theirs, usually either work only one shift (like apparel), or three shifts (like Petroleum). The latter are usually called continuous industries. The continuous ( 24 hours a day) utilization of the capital in these industries is 


\begin{tabular}{cccc} 
Variant & 1929 & 1976 & Change(\%) \\
\hline \hline$A^{a}$ & 66.5 & 81.8 & 23.0 \\
$B^{b}$ & 91.9 & 110.3 & 20.0 \\
$C^{c}$ & - & - & 24.7 \\
\hline
\end{tabular}

Source: Foss (1981a,b)

${ }^{a}$ Hours for each industry (at a four and two digit level) weighted by employment in each year.

${ }^{b}$ Hours for each industry (at a four and two digit level) weighted by capital in each year.

${ }^{c}$ Hours for each industry at the four digit level constructed as in $B$ and aggregated using as weights the gross fixed capital stock for 1954 in 1972 prices.

Table 1: Alternative measures of average weekly plant hours in manufacturing and their change, 1929 to 1976

usually related to very high costs of stopping and restarting production ${ }^{14}$. Foss finds that if we excluded these two types of industries the increase in average weekly plant hours reaches 32.4 percent between 1929 and 1976.

Finally Foss (1995) is able to construct annual indices based on actual annual observations of utilization for the period 1976 to 1988. The results are depicted on the right hand side of the dashed line of figure 2 . The series presents the expected cyclical fluctuations.

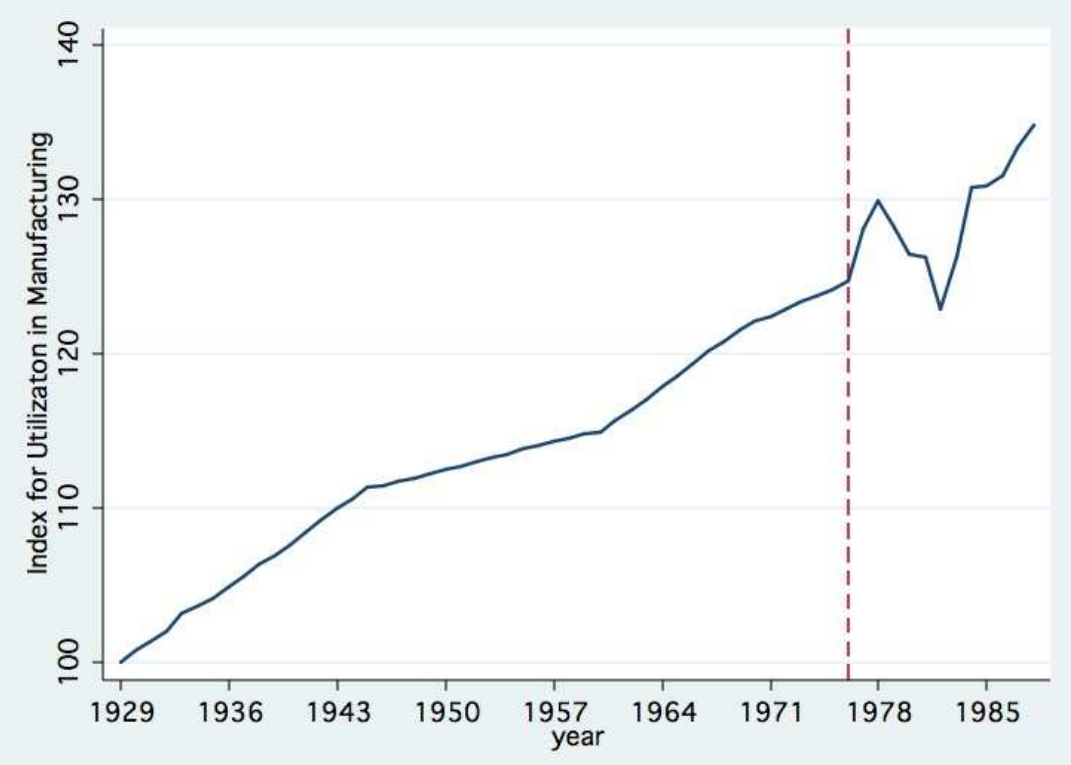

Figure 2: Index for the average workweek of capital in manufacturing $(1929=100)$ based on Foss (1984) and Foss (1995).

The Average Workweek of Capital (AWW) has been also estimated by other researchers. Taubman and Gottschalk (1971) estimate AWW for the period 1952 to 1968. The logic behind

\footnotetext{
${ }^{14}$ In this case, the adjustment of utilization takes place through a change in the speed of production.
} 
their effort is that the amount of the services of the capital stock can change either by varying the speed of operation or by varying the time the capital stock operates. Assuming that the speed of operation remains constant, the most common method of altering the time of operation of the capital stock is by changing the number of shifts it operates. Therefore, the amount of capital services can be estimated using the information of how many workers are employed in each of the three shifts ${ }^{15}$. Orr (1989), using the same methodology, extends the estimation for the period until 1984.

Their estimates are presented in figure 3a. It is clear that the utilization of capital presents pro-cyclical fluctuations and that there is an upward trend of the utilization of capital. Both papers run simple linear regressions and find statistically significant positive trends.

The same methodology is also followed by Shapiro (1986) for estimating the average workweek of capital for the period 1952 to 1982 . He follows Taubman and Gottschalk until 1968. For the period 1969 to 1982 he uses his own estimates of national level data on shift-work and the workweek of labor. As a result, there is a serious downward break in the series in 1968 which interrupts the positive trend. Therefore, the overall series estimated by Shapiro present a weaker, nonetheless positive, trend. The fact that the series begin from a year at the peak of the cycle and end at a year at the bottom of the cycle also contribute to that. Shapiro's estimates are presented in figure $3 \mathrm{~b}$ below.

Finally, Beaulieu and Mattey (1998) use the Survey of Plant Capacity (SPC), which contains series on the number of days per week and the number of hours per day the plant was in operation. The basic unit of observation is the product of these two series. They calculate the workweek of capital with different weighting techniques (employment per shift, employment, book value of capital, SPC sampling weights) for the period 1974-1992 ${ }^{16}$. The weighting scheme is important regarding the level and the trend of the workweek of capital. However, their conclusions are similar to the previous estimates. The trend of the utilization is positive ${ }^{17}$ and it presents pro cyclical fluctuations. We present their estimates with fixed employment per shift weights in figure $3 \mathrm{c}$.

From all the above efforts for estimating the workweek/utilization of capital, we conclude that utilization, aside from the expected pro-cyclical fluctuations, is far from stationary and has an upward trend over time. This comes in stark contrast with the horizontal trend of the FRB data on utilization. As a result, these data do not disprove the Kaleckian claim that there is an endogenous rate of utilization in the long run.

The remaining question to be answered is if there is a way to link the cyclical fluctuations of utilization with its trend. Until now in the literature the two phenomena are treated separately.

\footnotetext{
${ }^{15}$ The necessary data come from the Area Wage Surveys of the Bureau of Labor Statistics.

${ }^{16}$ Due to lack of data when they use the book value of capital they do it only for the period 1974-1985.

${ }^{17}$ When they use the book value of capital the positive trend is statistically insignificant. This is mot probably related to the particular period of estimation (1974-1985).
} 


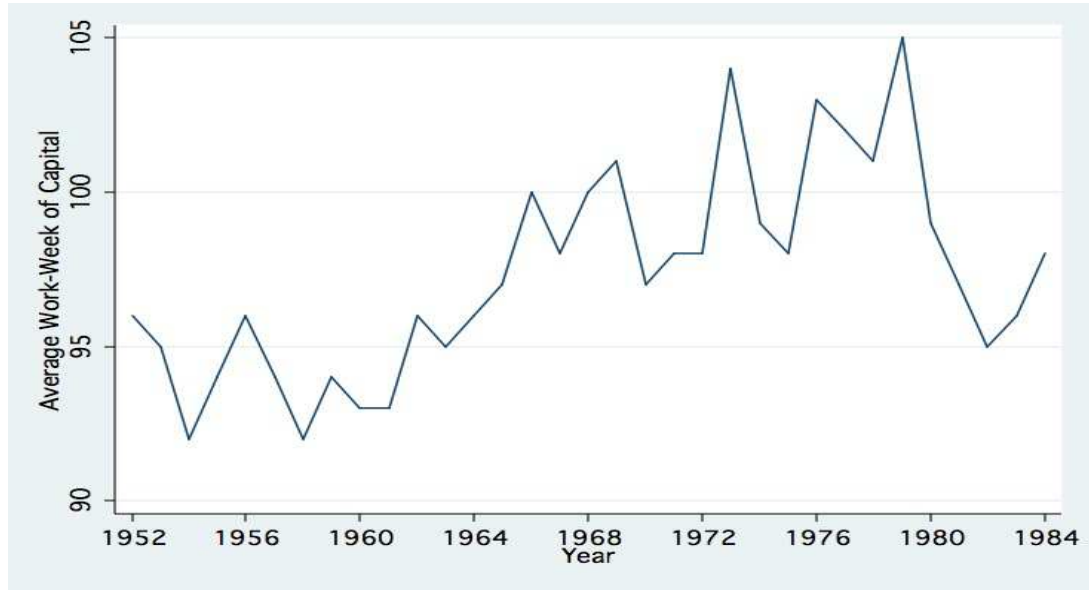

(a) Index for the average workweek of capital in manufacturing (1966=100) based on Taubman and Gottschalk (1971) and Orr (1989).

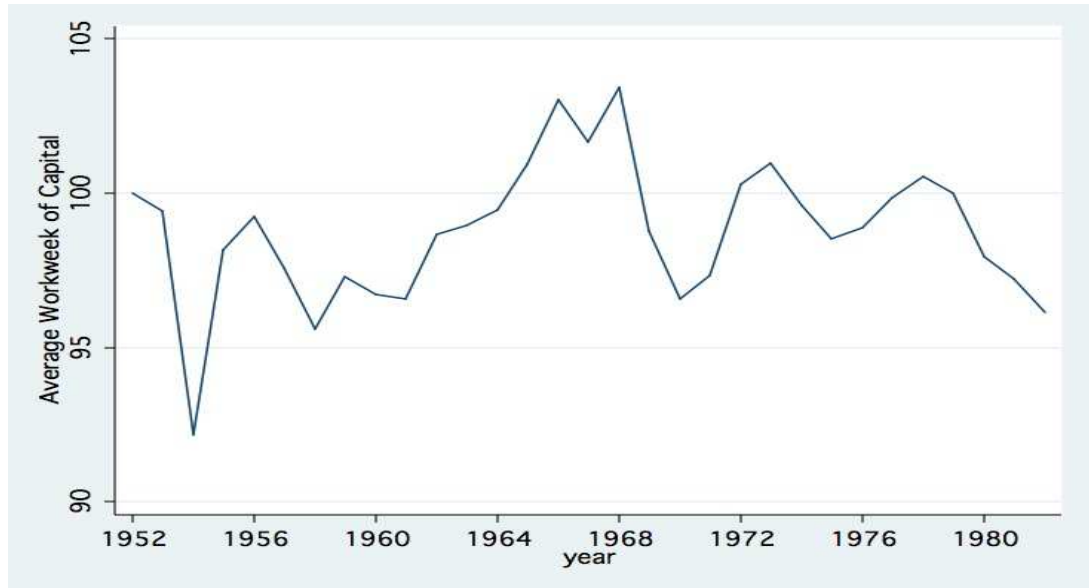

(b) The average workweek of capital in manufacturing $(1952=100)$ from Shapiro (1986).

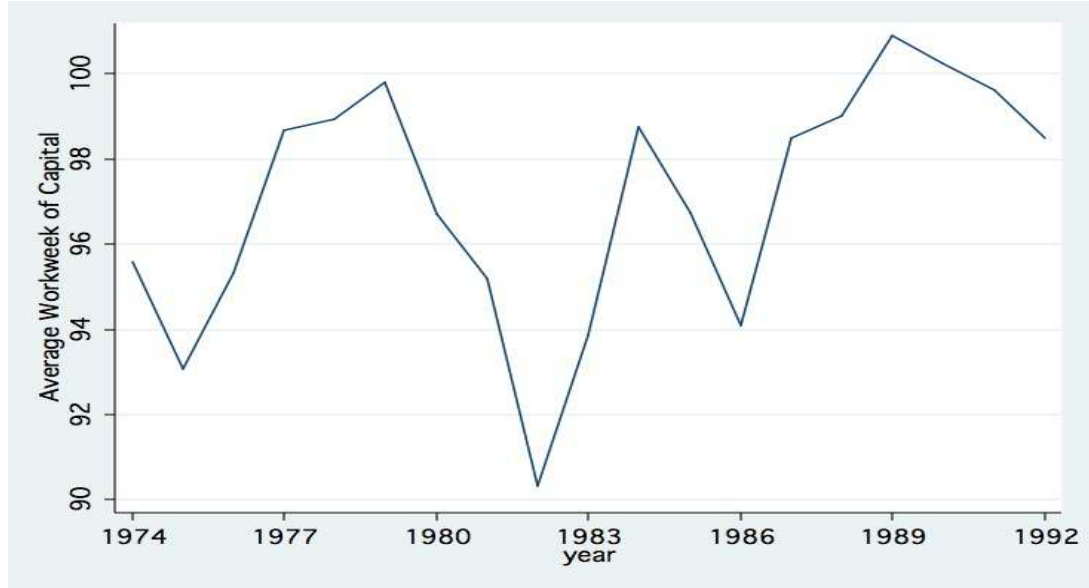

(c) The average workweek of capital in manufacturing from Beaulieu and Mattey (1998).

Figure 3: Measurements of the Average Workweek of Capital 
We take up these questions in the next sections.

\section{The (Normal) Rate of Capacity Utilization at the Firm Level}

As we mentioned above, the critique against the Kaleckian model has its origin at the firm level. The critics of the model argue - rightly - that the firm determines its desired level of utilization based on a cost-minimization (or profit-maximization process). Using Sraffa's (1960) word the choice "will be exclusively grounded on cheapness." Moreover, as Kurz (1986) has shown a cost-minimizing firm will not change its normal utilization rate in the face of changes in demand for its product. Thus, changes in demand will change the actual utilization rate of the firm, but in the long run the actual rate will tend to return to its exogenous normal level.

The argument of Kurz goes as follows: suppose that the demand for the product of a firm is $\bar{Q}$ and there is only one technique of production available. The firm uses only labor and capital as inputs. For the production of $\bar{Q}$, it needs a certain amount of capital $(K)$ and labor $(L)$. The utilization of capital can vary only through the time the capital is used, by adopting a single-shift system (a workweek of 40) or a double-shift system (a workweek of 80 hours). In the singleshift system capital , $K^{1}$, and labor, $L^{1}$, are combined to produce $\bar{Q}$. In the double shift system, half of the product is produced in the first shift and half in the second shift. In this case an amount of capital $K^{2}=K^{1} / 2$ is combined with an amount of labor $L^{21}$ in the first shift and $L^{22}$ in the second to produce $\bar{Q}$. The first number of the superscript refers to the system of operation and the second (if there) to the particular shift within each system. The amount of labor in the two shifts is equal, so $L^{21}=L^{22}=L^{2}=L^{1} / 2$. Increased utilization implies higher cost of labor for the second shift. Firms have to pay a utilization differential, $\frac{w_{2}}{w_{1}}=1+a$, where $w_{1}$ and $w_{2}$ are the wage for working in the morning and evening shift and $a>0$. Finally, $r$ is the unit cost of capital.

The total cost of production under the first system will be $C^{1}=r K^{1}+w_{1} L^{1}$, Under the double shift system the cost of production is $C^{2}=r K^{2}+w_{1} L^{21}+w_{2} L^{22}=r K^{2}+(2+a) w_{1} L^{2}$. We can define the cost ratio of the double shift system over the single shift system as $\Lambda=\frac{C^{2}}{C^{1}}=$ $\frac{1}{2}[\pi+(2+a) \psi]$, where $\pi$ is the share of capital cost and $\psi=1-\pi$ is the share of wage cost to the total cost of production under the single shift system respectively. The firm will choose the "cheapest" system of production. The double shift system will be chosen as long as $\Lambda<1$.

It is easy to see that $\Lambda$ is invariant to changes in demand, $\partial \Lambda / \partial \bar{Q}=0$. The choice of the system of production and thus the normal utilization will only change due to technological change or changes in the cost of labor and capital and of course changes in the utilization differential.

In a recent paper Nikiforos (2012) argues that this conclusion can change if we take into account the role of the economies of scale in production. Assume that the production with the single shift system gives rise to some economies of scale vis-à-vis the double shift system. and that 
these economies of scale depend on the level of the production of the firm. If $\zeta(\bar{Q})$ stands for these economies of scale, the cost ratio becomes

$$
\Lambda=[\pi+(2+a) \psi] \frac{\zeta(\bar{Q})}{2}
$$

In this case the cost ratio-and thus the choice of the system of production and utilizationis not invariant to demand, $\partial \Lambda / \partial \bar{Q}=[\pi+(2+a) \psi] \frac{\zeta^{\prime}(\bar{Q})}{2} \neq 0$. Moreover, $\partial \Lambda / \partial \bar{Q}<0$ if $\zeta^{\prime}(\bar{Q})<$ 0 . The entrepreneur will tend to choose a double shift system of operation over a single shift system of operation as the demand for the product of her firm increases, if the degree of the returns of scale decreases as the scale of production increases. Nikiforos (2012) shows how this conclusion can be extended to a technology with more than one technique of production and an infinite continuum of techniques of production.

Most importantly with the help of the theory of the economies of scale, it can be shown that this condition (the degree of the returns of scale decreases as the scale of production increases) is not just a "theoretical sophistry". The factor which is usually identified as a source of returns to scale is indivisibilities. Kaldor (1934) mentions that "it appears methodologically convenient to treat all cases of large-scale economies under the heading indivisibility" while Koopmans (1957, p.152) writes "I have not found one example of increasing returns to scale in which there is not some indivisible commodity in the surrounding circumstances". The benefits due to indivisibilities are exhausted as production increases and thus the degree of the returns to scale is decreasing. As a result the firm will tend to utilize its capital more as the demand for its product increases.

This conclusion is intuitive. The inputs of production are not perfectly divisible and the entrepreneur will necessary underutilize some of them. The necessary condition to increase their utilization is the increase for the demand of the product of the firm. Georgescu-Roegen (1969, 1970,1972) makes a similar argument. He argues that during the production of any good there are inevitably some idle resources and the degree of this idleness can only be reduced if the demand for the output of the firm increases.

This kind of behavior is verified by the answers of the entrepreneurs when they are asked what are the main factors that determine their decision about the utilization of their capital. In the second page of his [The] economics of capital utilisation Robin Marris (1964) writes

"in business inquiries, one of the commonest reasons given for working shifts or not (as the case may be) relates to demand [emphasis added]."

Roger Betancourt and Christopher Clague (also on page 2) of their Capital Utilization (1981) write

"interviews have shown that that when factory managers have been asked why they 
are operating only one shift one of the most frequent answer given is that the firm would not be able to sell its product [emphasis added]."

In conclusion, if we take into account (the behavior of) the returns to scale it appears plausible that at the firm level, the normal utilization rate is endogenous and positively correlated to the level of the demand for the product of the firm ${ }^{18}$.

\section{Revisiting the Kaleckian Model; from micro to macro}

As we mentioned in section 3 the main difficulty with the long run extension of the Kaleckian model is the unconvincing economic narrative behind equation (5). In the previous section we showed that as long as the rate of the economies of scale is decreasing the entrepreneurs will have the incentive - under the cost minimizing principle - to meet the increasing demand for the product of their firms not by expanding their plants, but rather by utilizing them more, that is by readjusting their desired rate of utilization upwards. A remaining task then is to relate this conclusion with the macro level.

Looking at the Statistics about Business Size from the U.S. Census Bureau ${ }^{19}$ we can see that the average firm size does not increase in line with the output. Increased aggregate demand at the macro level is accommodated through an increase in the number of the firms. The average firm size seems to increase in periods of high growth rates, periods when the growth rate is higher than the expected growth rate. Formally we could express this micro-macro relation as

$$
\dot{Q}=\theta\left(g^{*}-g_{0}\right)
$$

where $\theta$ is a positive parameter, $Q$ is the demand for the product of the firm and $g_{0}$ is the expected rate of accumulation .

In other words, a growth rate higher than the expected rate expands the market for the individual firm and increases the demand for its product. In the face of the increase in demand, the firm will increase its product ${ }^{20}$. This increase will tend to materialize through an increase in the (desired) utilization of the capital of the firm for the reasons we explained in the previous section.

\footnotetext{
${ }^{18}$ Nikiforos (2012) discusses in more detail the role of indivisibilities as a source of economies of scale. He also examines other causes of increasing returns following the taxonomy ofKaldor (1972).

${ }^{19} \mathrm{http}: / / \mathrm{www} . c e n s u s . g o v / e p c d / w w w / s m a l l b u s . h t m l \#$ Nonemployers

${ }^{20}$ Sraffa (1926) says in that respect: "Everyday experience shows that a very large number of undertakings-and the majority of those which produce manufactured consumers' goods-work under conditions of individual diminishing costs. Almost any producer of such goods, if he could rely upon the market in which he sells his products being prepared to take any quantity of them from him at the current price, without any trouble on his part except that of producing them, would extend his business enormously".
} 


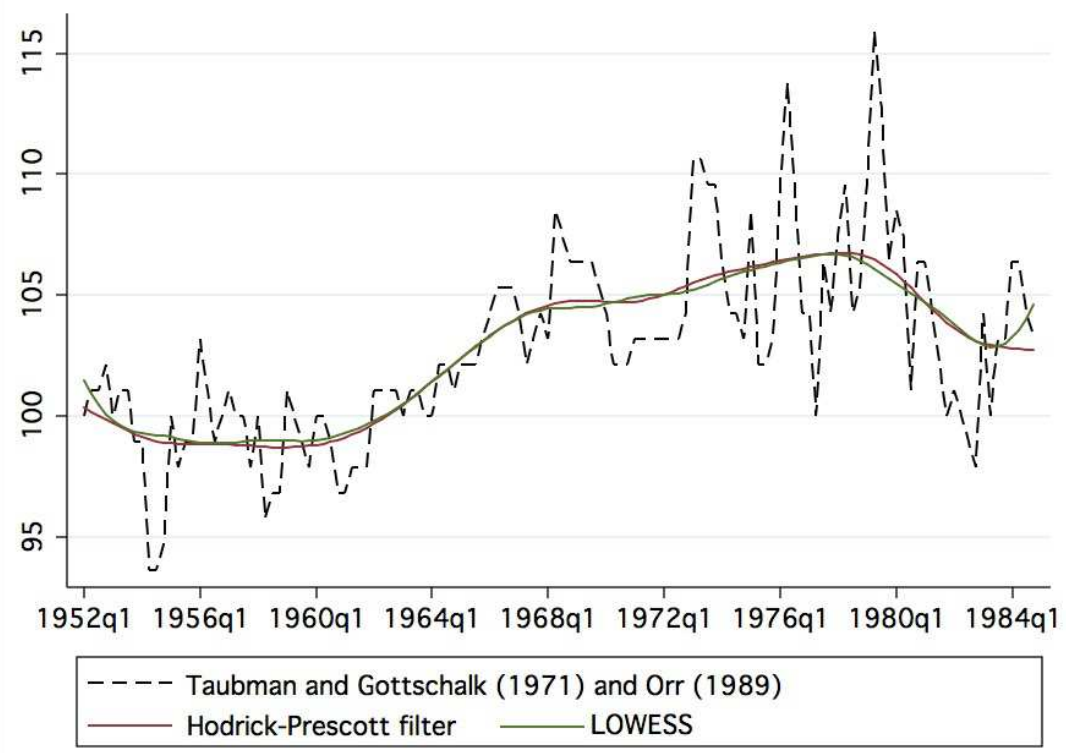

Figure 4: The series by Taubman and Gottschalk (1971) and Orr (1989) and its trend derived with the Hodrick-Prescott filter and the LOWESS method.

On the macro level, the growth of demand and output above their expected rates cause the level of the desired utilization to increase, $\dot{u}_{d}=\lambda\left(g^{*}-g_{0}\right)$, where $\lambda$ is a positive constant. From this equation and with the help of equations 1 and (3) it is easy to see that

$$
\dot{u}_{d}=\mu\left(u^{*}-u_{d}\right)
$$

where $\mu=\alpha \lambda>0$.

Equation (8) is the same with equation (5) and describes an endogenous adjustment of the desired utilization rate towards the actual rate. However, the logic towards equation (8) is different compared to the rationale that has been provided so far in the literature. We begin at the micro level, from a firm that explicitly sets its desired utilization rate based on a cost-minimizing decision process and then we provide a link of this micro behavior to the adjustment of utilization at the macro level.

\section{An empirical examination}

Our argument about the adjustment of the desired utilization rate along the lines described by equations (5) and (8) has been theoretical so far. In this section we will use the utilization data of the FRB and the series on the Average Workweek of capital to examine what the data say.

As we explained in section 4.3 the long run behavior of the average workweek of capital (AWW) is the right measure for the desired rate of utilization. We can therefore examine how 
the average workweek of capital reacts to the changes in the FRB data on utilization, which in turn are a proxy for the deviation of the actual rate from the desired rate $\left(u^{*}-u_{d}\right)$. We will use the series by Taubman and Gottschalk (1971) and Orr (1989) (presented in figure 3a) because it is the longer series among the different studies; from 1952q1 to $1984 q 4$.

As we also mentioned the average workweek of capital presents cyclical fluctuations. However, we would like to focus on its long run trend, which represents the desired rate of utilization. We use two different filters to obtain the trend of the AWW series: i) the Hodrick and Prescott (1997) filter and the "locally weighted least squares (LOWESS) method (Cleveland, 1979, Cleveland and Devlin, 1988). Since the data are quarterly, we use a smoothing parameter $\lambda=1600$ for the former and a bandwidth $a=0.3$ for the latter. We use two different filters because usually the conclusions are very sensitive to the method used to derive the trend. The three series are presented in figure 4.

We use an autoregressive distributed lag (ARDL). More specifically we estimate

$$
\begin{aligned}
\Delta A W W_{t}^{h p} & =c+\sum_{i=1}^{p_{h p}} \beta_{i} \Delta A W W_{t-i}^{h p}+\sum_{j=0}^{q_{h p}} \gamma_{j} F E D_{t-j}+\sum_{k=0}^{r_{h p}} \delta_{k} \Delta F E D_{t-k}^{h p}+\varepsilon \\
\Delta A W W_{t}^{l w s} & =c+\sum_{i=1}^{p_{l w s}} \beta_{i} \Delta A W W_{t-i}^{l w s}+\sum_{j=0}^{q_{l w s}} \gamma_{j} F E D_{t-j}+\sum_{k=0}^{r_{l w s}} \delta_{k} \Delta F E D_{t-k}^{l w s}+\varepsilon
\end{aligned}
$$

where $A W W$ stands for the Average workweek of Capital and $F E D$ for the FRB utilization rate. $\Delta$ is the difference operator and the superscript $h p$ and $l w s$ refers to the method used to obtain the trend of the series; the HP-filter and the LOWESS method respectively.

We use the variable $\triangle F E D$ because we want to control for the variation of the $\triangle A W W$ which is a result of the variation of the filter. The cyclical nature of utilization results in fluctuations of the HP filter (or any other filter), without that meaning that the desired rate changes. This variation is mostly statistical. As we see in figure 1 when we apply the HP-filter to the FRB utilization data the resulting series has a certain - small - degree of variation. Moreover, this variation can be described by an equation of motion such as (5) because of the construction of the filter. In our estimation we want to control and isolate this effect.

It is also worth noting that the number of lags for each of the variables are different in each one of the specifications. We specify the number using the the Akaike (1974)and the Bayesian Information Criterion (Schwarz, 1978). We explain in detail the way we choose the number of lags in the Appendix. We end up with $\left\{p_{h p}, q_{h p}, r_{h p}\right\}=\{4,2,3\}$ and $\left\{p_{l w s}, q_{l w s}, r_{l w s}\right\}=$ $\{7,2,1\}$.

We present the detailed results of our estimation and our post-estimation tests in the Appendix. As we mention there the error terms when we estimate equation (9) do not have a constant variance - in other words the error terms are not homoskedastic. We try to solve this prob- 


\begin{tabular}{lccl}
\hline & HP-filter & HP-ARCH & LOWESS \\
\hline \hline$\lambda_{F E D}$ & $0.0370 * * *$ & $0.0440 * * *$ & $0.0317 * * *$ \\
& $(0.0000)$ & $(0.0000)$ & $(0.0015)$ \\
$\lambda_{F E D}^{h p}$ & $0.3052^{* * *}$ & $0.3808 * * *$ & \\
& $(0.0001)$ & $(0.0000)$ & \\
$\lambda_{F E D}^{l w s}$ & & $0.2253 * *$ \\
& & $(0.0402)$ \\
\hline P-values of the Wald Test in parentheses \\
$* * * \mathrm{p}<0.01, * * \mathrm{p}<0.05, * \mathrm{p}<0.1$ \\
\hline
\end{tabular}

Table 2: The long-run multipliers for equations (15) and (16)

lem by using the AutoRegressive Conditional Heteroskedasticity (ARCH) technique because an examination of the residuals suggests that different levels of forecast errors appear to occur in clusters. More specifically we assume an $\mathrm{ARCH}(1)$ process for the variance of the residuals. As we will see below the results of the simple Least Squares Regression and the ARCH approach are similar.

We are primarily interested in the long run multiplier of the FRB utilization on the average workweek of capital, $\lambda_{F E D}=\frac{\sum_{j} \gamma_{j}}{1-\sum_{i} \beta_{i}}$. We also calculate the long run multiplier for $\triangle F E D^{h p}$ and $\triangle F E D^{l w s} ; \lambda_{F E D}^{h p}$ and $\lambda_{F E D}^{l w s}$ respectively. We test these estimates with a linear Wald test. The null hypothesis in the case of $\lambda_{F E D}$ is $H_{0}: \sum_{j} \gamma_{j}=0$. Respectively in the case of $\lambda_{F E D}^{h p}$ and $\lambda_{F E D}^{l w s}$ the null hypothesis is $H_{0}: \sum_{k} \delta_{k}=0$.

The long run multipliers are presented in table 2 . In the first two columns we present the multipliers from the estimation of equation (9) with Least Squares and ARCH method. In the third column we present the multipliers from the estimation of equation (10).

The estimates for $\lambda_{F E D}$ are all positive. Moreover, we can reject the null hypothesis for all of them at the $1 \%$ level, except $\lambda_{F E D}^{l w s}$, for which we can reject it at the $5 \%$ level. These results confirm that the desired rate of utilization, as measured by the average workweek of capital, adjusts to the deviations of the actual from the desired rate of utilization, as measured by the FRB data on utilization and lend some justification to equation of motion (5). Finally, we can also see that that $\lambda_{F E D}^{h p}$ and $\lambda_{F E D}^{l w s}$ have the expected positive sign.

\section{Conclusion}

In the preceding sections we argued in favor of an endogenous adjustment of the desired rate of capacity utilization as the economy grows. This adjustment is a possible mechanism for the transfer of the conclusions of the Kaleckian model from the short run to the long run. 
Our argument proceeded in a linear fashion. First, we explained why in the long run the actual rate of utilization must be equal to the desired rate. The latter is determined at the firm level and "will be exclusively grounded on cheapness". We explained why the mechanism that has been proposed in favor of an endogenous desired rate of utilization is not convincing. We also showed why the skepticism against an endogenous long run rate of utilization is reinforced by the FRB data which show a constant long run center of gravitation.

However, as we argued next, these data do not provide a satisfactory answer to the question of the long run trend of the desired rate because, by construction they only show the deviations of the actual rate from the desired rate. We propose that one way to face this problem is to examine how much time capacity is utilized vis à vis a fixed time interval: a day, a week, a year. If utilization is examined through this prism, the long-run trend of the desired rate of utilization is far from stationary.

We then asked ourselves if there are reasons that make the desired rate react positively to changes in demand. We provided a simple model of a firm, which determines the level of utilization of its resources based on the cost minimizing principle. The firm has an incentive to increase the utilization as the production increases if the rate of degrees of scale decreases with the expansion of the scale of production. We argued that the theory of the economies of scale provides verification for such a behavior of the economies of scale.

We concluded that via this mechanism the firm will tend to increase the utilization of its resources along with its product as the economy grows and the firm faces increasing demand. At a macro level this can be "translated" into an endogenous adjustment of the desired level of utilization towards its actual rate. Finally, we provided an empirical examination of the proposed adjustment mechanism; our results confirm that the average workweek of capital adjusts to the deviations of the actual from the desired rate of utilization. 


\section{REFERENCES}

Akaike, H. 1974. “A New Look at the Statistical Model Identification.” IEEE Transactions on Automatic Control 19(6): 716-723.

Amadeo, E. J. 1986. "The Role of Capacity Utilization in the Long Period Analysis." Political Economy 2(2)" 147-160.

Auerbach, P. and P. Skott. 1988. "Concentration, Competition and Distribution - A Critique of Theories of Monopoly Capital." International Review of Applied Economics 2(1): 42-61.

Beaulieu, J. J. and J. Mattey. 1998. "The Workweek of Capital and Capital Utilization in Manufacturing." Journal of Productivity Analysis 10: 199-223.

Berndt, E. R. and C. J. Morrison. 1981. "Capacity Utilization Measures: Underlying Economic Theory and an Alternative Approach." The American Economic Review 71(2): 48-52.

Betancourt, R. R. and C. K. Clague. 1981. Capital Utilization: A Theoretical and Empirical Analysis. Cambridge, UK: Cambridge University Press.

Bresnahan, T. F. and V. A. Ramey. 1994. "Output Fluctuations at the Plant Level." The Quarterly Journal of Economics 109(3): 593-624.

Breusch, T. S. and A. R. Pagan. 1979. "A Simple Test for Heteroscedasticity and Random Coefficient Variation.” Econometrica 47(5): 1287-1294.

Cleveland, W. S. 1979. "Robust Locally Weighted Regression and Smoothing Scatterplots." Journal of the American Statistical Association 74(368): 829-836.

Cleveland, W. S. and S. J. Devlin. 1988. "Locally Weighted Regression: An Approach to Regression Analysis by Local Fitting." Journal of the American Statistical Association 83(403): 596-610.

Committeri, M. 1986. "Some Comments on Recent Contributions on Capital Accumulation." Political Economy 2(2): 161-186.

Corrado, C. and J. Mattey. 1997. “Capacity Utilization.” The Journal of Economic Perspectives 11(1): 151-167.

Cumby, R. E. and J. Huizinga. 1992. "Testing the Autocorrelation Structure of Disturbances in Ordinary Least Squares and Instrumental Variables Regressions." Econometrica 60(1): 185-195. 
Dumenil, G. and D. Levy. 1993. "Being Keynesian in the Short Term and Classical in the Long Term: The Traverse to Classical Long-Term Equilibrium." The Manchester School 67(6): 684-716.

Dutt, A. K. 1984. "Stagnation, Income Distribution and Monopoly Power." Cambridge Journal of Economics 8(1): 25-40.

1990. Growth, Distribution and Uneven Development. Cambridge, UK: Cambridge University Press.

1997. "Equilibrium, Path Dependence and Hystersis in Post-Keynesian Models." In P. Arestis, G. Palma, and M. Sawyer (Eds.), Capital Controversy, PostKeynesian Economics and the History of Economic Thought: Essays in Honour of Geoff Harcourt. London, UK: Routledge.

Federal Reserve. 2009. "Capacity Utilization Explanatory Notes." Economic Research and Data: Statistical Releases and Historical Data, March. http://www.federalreserve.gov/releases/G17/cap_notes.htm.

Foley, D. K. and T. Michl. 1999. Growth and Distribution. Cambridge, MA: Harvard University Press.

Foss, M. F. 1963. "The Utilization of Capital Equipment: Postwar Compared With Prewar." Survey of Current Business 43(6): 8-17.

- 1981a. Changes in the Workweek of Fixed Capital: U.S. Manufacturing, 1929 to 1976. Washington, DC: American Enterprise Institute for Public Policy Research.

_. 1981b. "Long-Run Changes in the Workweek of Fixed Capital." The American Economic Review 71(2): 58-63.

- 1984. Changing Utilization of Fixed Capital: An Element in Long-Term Growth. Washington, DC: American Enterprise Institute for Public Policy Research.

1995. "Operating Hours of the US Manufacturing Plants, 1976-1988, and their Significance for Productivity Change." In D. Anxo, G. Bosch, G. Cette, T. Sterner, and D. Taddei (Eds.), Work Patterns and Capital Utilisation: An International Comparative Study. London: Kluwer Academic Publishers.

Georgescu-Roegen, N. 1969. "Process in Farming Versus Process in Manufacturing: A Process of Balanced Development." In U. Papi and C. Nunn (Eds.), Economic Problems of Agriculture in Industrial Societies. London, UK: Macmillan.

— 1970. "The Economics of Production." The American Economic Review 60(2): $1-9$. 
- 1972. "Process Analysis and the Neoclassical Theory of Production." American Journal of Agricultural Economics 54(2): 279-294.

Harrod, R. 1939. “An Essay in Dynamic Theory.” Economic Journal 49(193): 14-33.

Hein, E., M. Lavoie, and T. van Treeck. 2012. "Harrodian Instability and the 'Normal Rate' of Capacity Utilisation in Kaleckian Models of Distribution and Growth-A Survey." Metroeconomica 63(1): 139-169.

Hodrick, R. J. and E. C. Prescott. 1997. "Postwar U.S. Business Cycles: An Empirical Investigation." Journal of Money, Credit and Banking 29(1): 1-16.

Kaldor, N. 1934. "The Equilibrium of the Firm.” The Economic Journal 44(173): 60-76.

- 1972. "The Irrelevance of Equilibrium Economics." The Economic Journal 82(328): 1237-1255.

Kalecki, M. 1971. Selected Essays on the Dynamics of the Capitalist Economy. Cambridge, UK: Cambridge University Press.

Klein, L. R. 1960. "Some Theoretical Issues in the Measurement of Capacity." Econometrica 28(2): 272-286.

Koopmans, T. C. 1957. Three Essays on the State Economic Science. New York, NY: McGraw-Hill.

Kurz, H. 1986. "Normal Positions and Capital Utilisation.” Political Economy 2(1): 3754.

- 1990. "Technical Change, Growth and Distirbution." In Capital Distribution and Effective Demand: Studies in the "Classical" Approach to Economic Theory. Cambridge, MA: Basil Blackwell.

Lavoie, M. 1995. "The Kaleckian Model of Growth and Distribution and Its NeoRicardian and Neo-Marxian Critiques." Cambridge Journal of Economics 19(6): 789-818.

- 1996. "Traverse, Hysteresis and Normal Growth Rates of Capacity Utilization in Kaleckian models of Growth and Distribution." Review of Radical Political Economy 28(4): 113-147.

Lavoie, M., G. Rodríguez, and M. Seccareccia. 2004. "Similitudes and Discrepancies in Post-Keynesian and Marxist Theories of Investment: A Theoretical and Empirical Investigation." International Review of Applied Economics 18(2): 127-149. 
Marglin, S. and A. Bhaduri. 1990. "Profit Squeeze and Keynesian Theory." In S. Marglin and J. Schor (Eds.), The Golden Age of Capitalism: Reinterpreting the Postwar Experience. Oxford, UK: Clarendon Press.

Marris, R. 1964. The Economics of Capital Utilisation: A Report on Multiple Shift Work. Cambridge, UK: Cambridge University Press.

Mattey, J. and S. Strongin. 1997. "Factor Utilization and Margins for Adjusting Output: Evidence from Manufacturing Plants." Federal Reserve Bank of San Francisco Economic Review (2): 3-17.

Morin, N. and J. Stevens. 2004. Estimating Capacity Utilization from Survey Data. Washington, DC: Division of Research \& Statistics and Monetary Affairs, Federal Reserve Board.

Morrison, C. J. 1985. "On the Economic Interpretation and Measurement of Optimal Capacity Utilization with Anticipatory Expectations." The Review of Economic Studies 52(2): 295-310.

Nikiforos, M. 2012. "The (Normal) Rate of Capacity Utilization at the Firm Level." Working Paper No. 737. Annandale-on-Hudson, NY: Levy Economics Institute of Bard College.

Nikiforos, M. and D. K. Foley. 2012. "Distribution and Capacity Utilization: Conceptual Issues and Empirical Evidence.” Metroeconomica 63(1): 200-229.

Orr, J. A. 1989. “The Average Workweek of Capital in Manufacturing, 1952-1984.” Journal of the American Statistical Association 84(405): 88-94.

Rowthorn, R. 1981. Demand, Real Wages and Economic Growth. London, UK: Thames Polytechnic.

Schwarz, G. E. 1978. "Estimating the Dimension of a Model." Annals of Statistics 6(2): 461-464.

Shaikh, A. 2009. "Economic Policy in a Growth Context: A Classical Synthesis of Keynes and Harrod." Metroeconomica 60(3): 455-494.

Shapiro, M. D. 1986. "Capital Utilization and Capital Accumulation: Theory and Evidence." Journal of Applied Econometrics 1(3): 211-234.

Skott, P. 2010. "Growth, Instability and Cycles: Harrodian and Kaleckian Models of Accumulation and Income Distribution." In M. Setterfield (Ed.), Handbook of Alternative Theories of Economic Growth. London, UK: Edward Elgar. 
—. 2012. "Theoretical and Empirical Shortcomings of the Kaleckian Investment Function." Metroeconomica 63(1): 109-138.

Spence, A. M. 1977. "Entry, Capacity, Investment and Oligopolistic Pricing." The Bell Journal of Economics 8(2): 534-544.

Sraffa, P. 1926. "The Laws of Returns under Competitive Conditions." The Economic Journal 36(144): 535-550.

-1960. Production of Commodities by Means of Commodities: Prelude to a Critique of Economic Theory. Cambridge, UK: Cambridge University Press.

Steedman, I. 1992. “Questions for Kaleckians.” Review of Political Economy 4(2): 125151.

Steindl, J. 1952. Maturity and Stagnation in American Capitalism. Oxford, UK: Basil Blackwell.

Taubman, P. and P. Gottschalk. 1971. "The Average Workweek of Capital in Manufacturing." Journal of the American Statistical Association 66(335): 448455.

Taylor, L. 1983. Structuralist Macroeconomics. New York, NY: Basil Books.

1990. "Real and Money Wages, Output and Inflation in the Semi-Industrialized World." Economica 57(227): 329-353.

- 2004. Reconstructing Macroeconomics: Structuralist Proposals and Critiques of the Mainstream. Cambridge, MA: Harvard University Press.

Winston, G. C. 1974. "The Theory of Capital Utilization and Idleness." Journal of Economic Literature 12(4): 1301-1320. 


\section{Appendix}

\section{A The Kaleckian model in the long run}

From equations (1) and (3) we can derive the equilibrium level of the growth rate in the short run:

$$
g^{*}=s \pi \rho u^{*}=s \pi \rho \frac{\gamma-\alpha u_{d}+\beta \pi}{s \pi \rho-\alpha}
$$

Equations (3) and (11) define a short run equilibrium, where the desired rate of utilization is exogenous. In the long run the desired rate becomes endogenous and behaves according to equation (5). To "close" the system Lavoie $(1995,1996)$ and Dutt (1997) supplement equation (5) with the following dynamic equation

$$
\dot{\gamma}=\theta\left[g^{*}-(\gamma+\beta \pi)\right]
$$

where $\gamma+\beta \pi$ represents the expected rate of accumulation and $\theta>0$. If the actual rate of accumulation exceeds the expected rate, firms revise their expectations about the growth rate upwards; an argument with Harrodian flavor ${ }^{21}$. This dynamic equation can be rewritten as

$$
\dot{\gamma}=\theta\left[a\left(u^{*}-u_{d}\right)\right]
$$

Equations (5) and (13) define a $2 \times 2$ system of dynamic equations. Substituting the equilibrium values of utilization it becomes

$$
\begin{aligned}
& \dot{u}_{d}=\mu\left(\frac{\gamma-\alpha u_{d}+\beta \pi}{s \pi \rho-\alpha}-u_{d}\right) \\
& \dot{\gamma}=\alpha \theta\left(\frac{\gamma-\alpha u_{d}+\beta \pi}{s \pi \rho-\alpha}-u_{d}\right)
\end{aligned}
$$

The Jacobian matrix of this system is zero. For stability, it is required that the trace of the Jacobian is negative, that is $\mu s \pi \rho>\alpha \theta$. The sufficient condition for this to hold-because of the Keynesian stability condition - is $\mu>\theta$, that is the adjustment of the desired utilization rate is faster than the adjustment of the desired growth rate. The system has an infinite number of equilibria. The steady state depends on the initial equilibrium and the path of the economy towards it.

As we mentioned in section 3.2 the economy remains demand driven in the long run: the paradox of thrift and the paradox of cost continue to hold. A higher saving rate will lead the economy to a steady state with a higher level of utilization and growth rate. Interestingly, in the

\footnotetext{
${ }^{21}$ See Harrod (1939).
} 
long run the economy cannot be profit-led. A higher profit share decreases the steady state level of utilization and growth.

\section{B The choice of the number of lags}

Here we rewrite equations (9) and (10)

$$
\begin{aligned}
\Delta A W W_{t}^{h p} & =c+\sum_{i=1}^{p_{h p}} \beta_{i} \Delta A W W_{t-i}^{h p}+\sum_{j=0}^{q_{h p}} \gamma_{j} F E D_{t-j}+\sum_{k=0}^{r_{h p}} \delta_{k} \Delta F E D_{t-k}^{h p}+\varepsilon \\
\Delta A W W_{t}^{l w s} & =c+\sum_{i=1}^{p_{l w s}} \beta_{i} \Delta A W W_{t-i}^{l w s}+\sum_{j=0}^{q_{l w s}} \gamma_{j} F E D_{t-j}+\sum_{k=0}^{r_{l w s}} \delta_{k} \Delta F E D_{t-k}^{l w s}+\varepsilon
\end{aligned}
$$

A first step towards the estimation of these equations is the specification of the number of lags for the autoregressive part and the independent variables: $\left\{p_{h p}, q_{h p}, r_{h p}\right\}$ and $\left\{p_{l w s}, q_{l w s}, r_{l w s}\right\}$. We use the following method:

Step 1 We estimate the Akaike Information Criterion (AIC) and the Bayesian Information Criterion (BIC) for different lag structures of the autoregressive part, conditionally to a certain lag structure of the independent variables.

Step 2 For the optimal lag structure from the step 1 we estimate AIC and BIC for different lag structures of the independent variables.

Step 3 We repeat steps 1 and 2 until the optimal lag structure for the independent variables of

Step-2 is the "exogenous" structure used in Step-1 and the optimal lag-structure for the Autoregressive part of step 1 is the "exogenous" structure used in step 2.

We present the information criteria for the autoregressive part in table 3 for $\left\{q_{h p}, r_{h p}\right\}=$ $\{2,3\}$ and $\left\{q_{l w s}, r_{l w s}\right\}=\{2,1\}$. It is clear that the value of both criteria is minimized for $p=4$ in the case of the HP-filtered series and $p=7$ when we apply the LOWESS method.

In tables 4 and 5 we present the information criteria for different lag structures of the independent variables for $p_{h p}=4$ and $p_{l w s}=7$. In the case of the HP-filtered series, both criteria are minimized for $\left\{q_{h p}, r_{h p}\right\}=\{2,3\}$. In the case of the LOWESS method, both criteria are minimized for $q_{l w s}=2$. However the AIC points to $r_{l w s}=3$ and the BIC to $r_{l w s}=1$. The two specifications produce similar long run estimates. We present the results of the latter specification.

In conclusion we choose the following length structure for the estimation of equations (15) and (16): $\left\{p_{h p}, q_{h p}, r_{h p}\right\}=\{4,2,3\}$ and $\left\{p_{l w s}, q_{l w s}, r_{l w s}\right\}=\{7,2,1\}$. 


\begin{tabular}{|c|cc|cc|}
\cline { 2 - 5 } \multicolumn{1}{c|}{} & \multicolumn{2}{c|}{ HP-filter } & \multicolumn{2}{c|}{ LOWESS } \\
\hline lag & AIC & BIC & AIC & BIC \\
\hline \hline 0 & -3.1595 & -2.9765 & -2.4018 & -2.2528 \\
1 & -6.6819 & -6.4761 & -5.8798 & -5.7060 \\
2 & -9.5245 & -9.2959 & -7.6469 & -7.4482 \\
3 & -10.6511 & -10.3996 & -9.6079 & -9.3844 \\
4 & $-10.7758^{*}$ & $-10.5015^{*}$ & -10.0053 & -9.7569 \\
5 & -10.7597 & -10.4625 & -10.0922 & -9.8190 \\
6 & -10.7521 & -10.4320 & -10.1231 & -9.8251 \\
7 & -10.7459 & -10.4029 & $-10.1674^{*}$ & $-9.8445^{*}$ \\
8 & -10.7322 & -10.3664 & -10.1556 & -9.8079 \\
\hline
\end{tabular}

Table 3: The Akaike and the Bayesian Information Criteria for the Autoregressive Part of equations (15) and (16)

\section{Estimates \& Post-estimation}

The estimates of equations (9) and (10) - or equivalently (15) and (16) - are presented in table 6 . In the first two columns we present the multipliers from the estimation of equation 9 with Least Squares and ARCH method. In the third column we present the multipliers from the estimation of equation (10).

In table 7 we present the results of the tests that we performed for autocorrelation and heteroskedasticity for the Least Squares estimation of our two equations. We use the Cumby and Huizinga (1992) test for autocorrelation and the Breusch and Pagan (1979) test for heteroskedasticity. The null hypothesis is that there is no failure of autocorrelation and heteroskedasticity. We fail to reject the null hypothesis for autocorrelation. In the case of heteroskedasticity we reject the null hypothesis of constant variance of the residuals for the first equation.

The failure in the Breusch and Pagan (1979) test in the case of equation (9) leads us to estimate the same equation with an $\mathrm{ARCH}(1)$ specification. In other words we assume the following process for the variance of the residuals $\sigma_{t}^{2}=\alpha_{0}+\alpha_{1} \varepsilon_{t-1}^{2}$. Our estimates for $\alpha_{1}$ and $\alpha_{0}$ are $1.708 * * *(-0.356)$ and $1.30 \mathrm{e}-07 * *(-5.33 \mathrm{E}-08)$ respectively ${ }^{22}$.

\footnotetext{
${ }^{22}$ As usual standard errors in parentheses and $* * * \mathrm{p}<0.01, * * \mathrm{p}<0.05,{ }^{*} \mathrm{p}<0.1$
} 


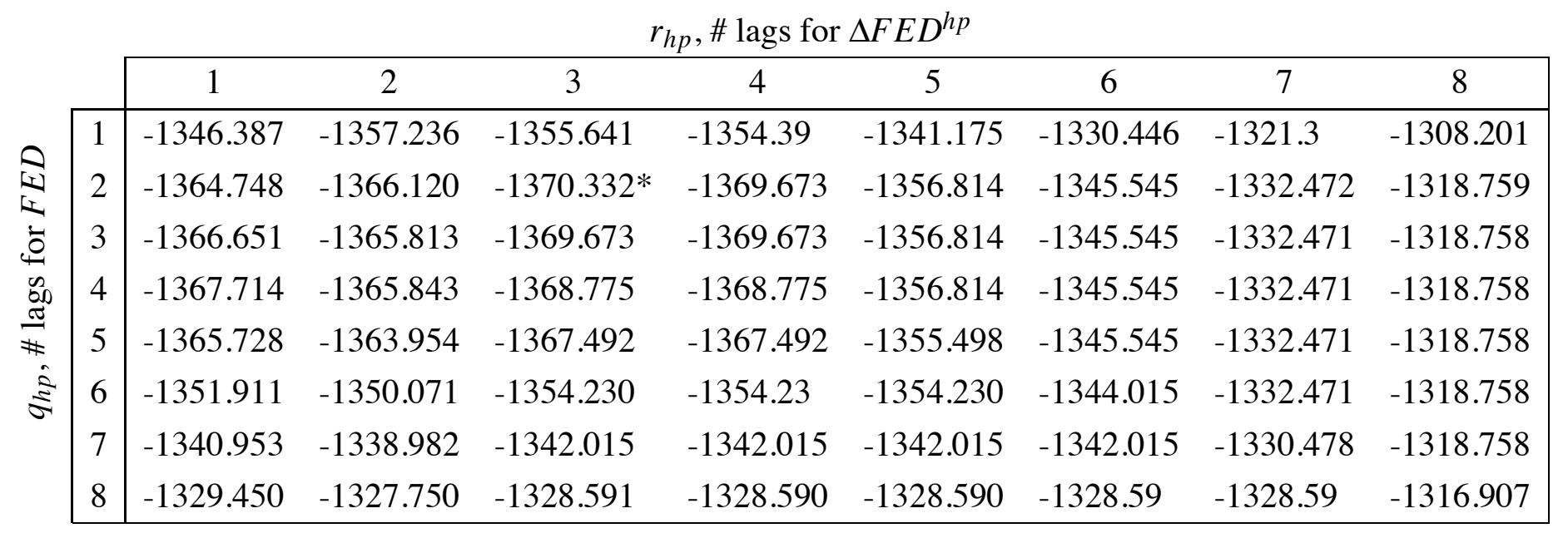

(a) The Akaike Information Criterion

\begin{tabular}{|c|c|c|c|c|c|c|c|c|c|}
\hline & & & & & , \# lags for & $F E D^{h p}$ & & & \\
\hline & & 1 & 2 & 3 & 4 & 5 & 6 & 7 & 8 \\
\hline & 1 & -1320.79 & -1328.794 & -1324.355 & -1320.26 & -1304.303 & -1290.849 & -1278.996 & -1263.206 \\
\hline & 2 & -1336.113 & -1334.834 & $-1336.202^{*}$ & -1332.699 & -1317.106 & -1303.12 & -1287.347 & -1270.951 \\
\hline & 3 & -1335.365 & -1331.682 & -1332.698 & -1332.698 & -1317.106 & -1303.12 & -1287.347 & -1270.951 \\
\hline & 4 & -1333.584 & -1328.868 & -1328.957 & -1328.956 & -1317.106 & -1303.12 & -1287.347 & -1270.951 \\
\hline & 5 & -1328.753 & -1324.135 & -1324.829 & -1324.829 & -1312.954 & -1303.12 & -1287.347 & -1270.951 \\
\hline s & 6 & -1312.203 & -1307.526 & -1308.85 & -1308.849 & -1308.849 & -1298.762 & -1287.347 & -1270.951 \\
\hline & 7 & -1298.528 & -1293.729 & -1293.934 & -1293.934 & -1293.934 & -1293.934 & -1282.533 & -1270.951 \\
\hline & 8 & -1284.325 & -1279.805 & -1277.825 & -1277.825 & -1277.825 & -1277.825 & -1277.825 & -1266.288 \\
\hline
\end{tabular}

(b) The Bayesian Information Criterion

Table 4: The Akaike and the Bayesian Information Criteria for the independent variables when we derive the trend with the HP-filter 


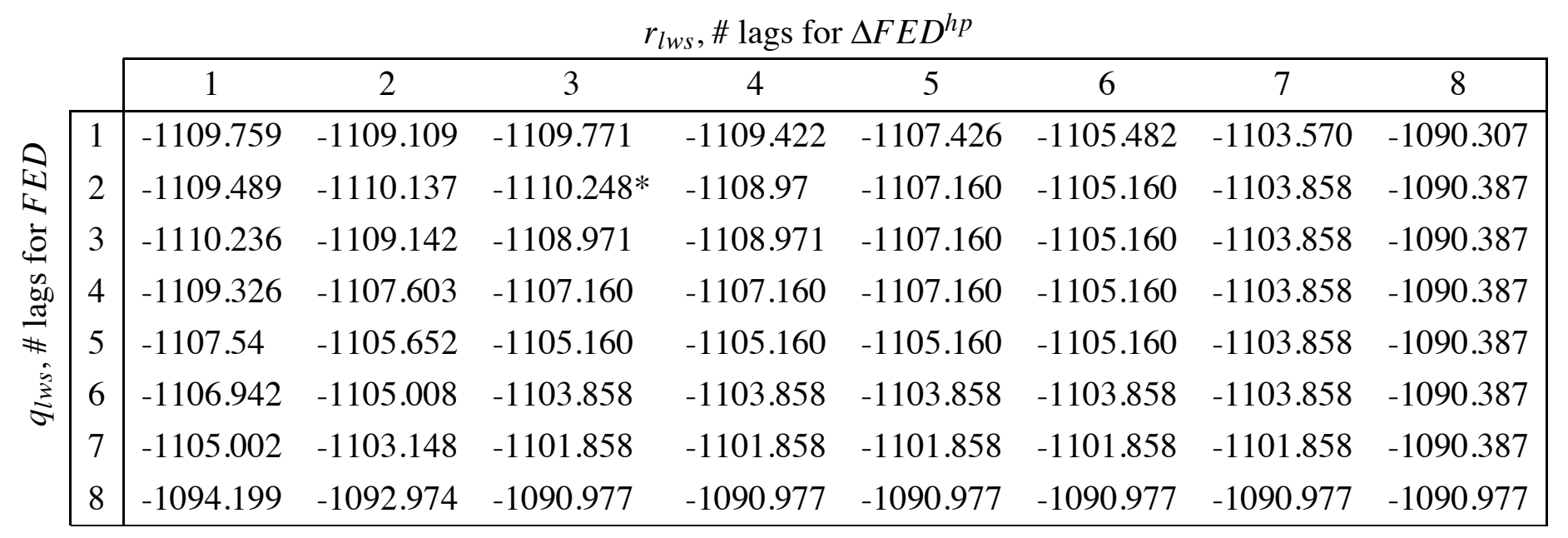

(a) The Akaike Information Criterion

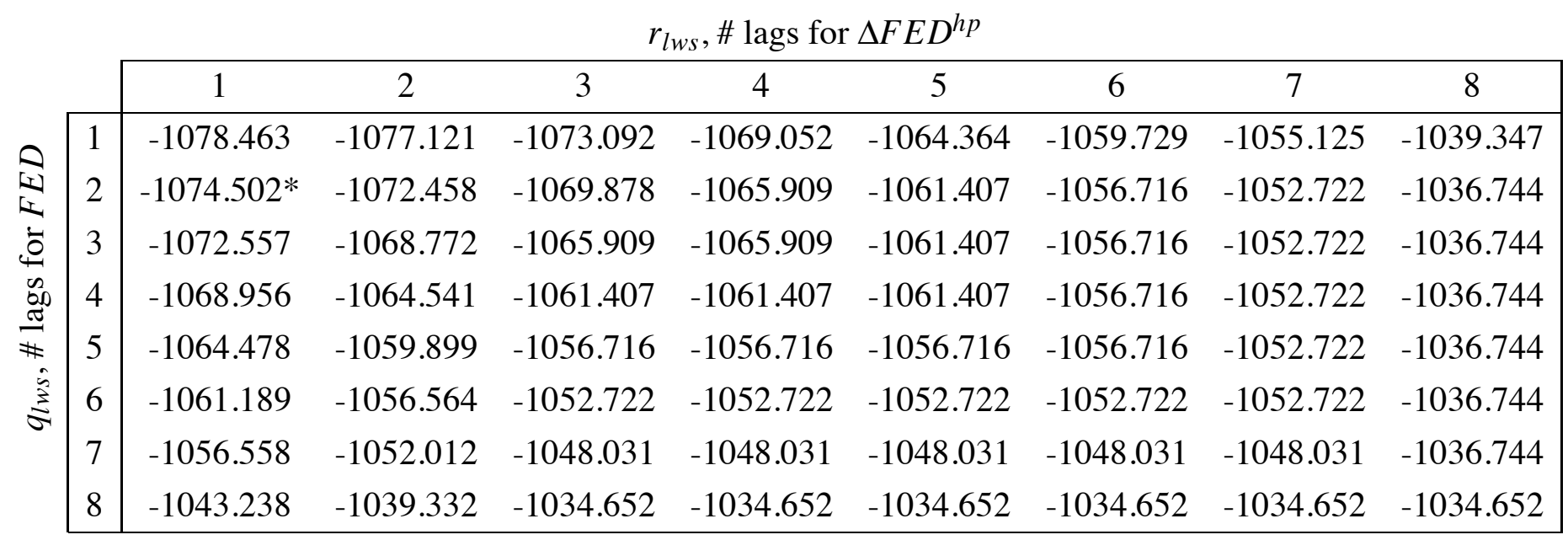

(b) The Bayesian Information Criterion

Table 5: The Akaike and the Bayesian Information Criteria for the independent variables when we derive the trend with the LOWESS method 


\begin{tabular}{|c|c|c|c|}
\hline & HP-filter & HP-ARCH & LOWESS \\
\hline \multirow[t]{2}{*}{$\Delta A W W_{t-1}$} & $2.941 * * *$ & $2.787 * * *$ & $3.523 * * *$ \\
\hline & $(-0.083)$ & $(-0.050)$ & $(-0.106)$ \\
\hline \multirow[t]{2}{*}{$\Delta A W W_{t-2}$} & $-3.282 * * *$ & $-2.805 * * *$ & $-5.261 * * *$ \\
\hline & $(-0.226)$ & $(-0.149)$ & $(-0.393)$ \\
\hline \multirow[t]{2}{*}{$\Delta A W W_{t-3}$} & $1.648 * * *$ & $1.173 * * *$ & $4.185 * * *$ \\
\hline & $(-0.221)$ & $(-0.151)$ & $(-0.697)$ \\
\hline \multirow[t]{2}{*}{$\Delta A W W_{t-4}$} & $-0.316^{* * *}$ & $-0.161 * * *$ & $-1.593 *$ \\
\hline & $(-0.077)$ & $(-0.051)$ & $(-0.808)$ \\
\hline \multirow[t]{2}{*}{$\Delta A W W_{t-5}$} & & & $(-0.283)$ \\
\hline & & & $(-0.672)$ \\
\hline \multirow[t]{2}{*}{$\Delta A W W_{t-6}$} & & & $0.665 *$ \\
\hline & & & $(-0.364)$ \\
\hline \multirow[t]{2}{*}{$\Delta A W W_{t-7}$} & & & $-0.244 * *$ \\
\hline & & & $(0.113)$ \\
\hline \multirow[t]{2}{*}{$F E D_{t}$} & $5.43 \mathrm{E}-05$ & $-3.94 \mathrm{E}-06$ & $4.05 \mathrm{E}-05$ \\
\hline & $(-6.09 \mathrm{E}-05)$ & $(-3.04 \mathrm{E}-05)$ & $(-7.73 \mathrm{E}-05)$ \\
\hline \multirow[t]{2}{*}{$F E D_{t-1}$} & -8.30E-05 & 9.53E-06 & 0.000117 \\
\hline & $(-8.05 E-05)$ & $(-4.24 \mathrm{E}-05)$ & $(-0.000113)$ \\
\hline \multirow[t]{2}{*}{$F E D_{t-2}$} & $0.000358 * * *$ & $0.000279 * * *$ & $6.76 \mathrm{E}-05$ \\
\hline & $(-8.91 \mathrm{E}-05)$ & $(-4.71 E-05)$ & $(-8.42 \mathrm{E}-05)$ \\
\hline \multirow[t]{2}{*}{$\Delta F E D_{t}^{h p / l w s}$} & -0.193 & $-0.139 * *$ & $0.0369 * * *$ \\
\hline & $(-0.116)$ & $(-0.0683)$ & $(-0.0091)$ \\
\hline \multirow[t]{2}{*}{$\Delta F E D_{t-1}^{h p / l w s}$} & $0.696 * *$ & $0.554 * * *$ & $-0.0353 * * *$ \\
\hline & $(-0.346)$ & $(-0.201)$ & $(-0.00881)$ \\
\hline \multirow[t]{2}{*}{$\Delta F E D_{t-2}^{h p / l w s}$} & $-0.770 * *$ & $-0.653 * * *$ & \\
\hline & $(-0.342)$ & $(-0.197)$ & \\
\hline \multirow[t]{2}{*}{$\Delta F E D_{t-3}^{h p / l w s}$} & $0.270 * *$ & $0.241 * * *$ & \\
\hline & $(-0.112)$ & $(-0.0642)$ & \\
\hline \multirow[t]{2}{*}{ Constant } & $-0.0316 * * *$ & $-0.0275 * * *$ & $-0.0216 * * *$ \\
\hline & $(-0.00678)$ & $(-0.00342)$ & $(-0.00665)$ \\
\hline
\end{tabular}

Standard Errors in parentheses

$* * * \mathrm{p}<0.01, * * \mathrm{p}<0.05,{ }^{*} \mathrm{p}<0.1$

Table 6: The estimates for equations (15) and (16) 


\begin{tabular}{cllll}
\hline & \multicolumn{2}{c}{ Autocorrelation } & \multicolumn{2}{c}{ Heteroskedasticity } \\
\cline { 2 - 5 } & HP-filter & LOWESS & HP-filter & LOWESS \\
\hline Test-Statistic & 0.589 & 0.3878 & 7.740 & 2.430 \\
P-value & 0.442 & 0.5334 & 0.006 & 0.119 \\
\hline
\end{tabular}

Table 7: Tests for autocorrelation and heteroskedasticity. $H_{0}$ : there is no failure of autocorrelation and heteroskedasticity. 